\title{
APPLICATION FEATURES OF ULTRASONIC WELDING
}

\author{
Gyula BAGYINSZKI ${ }^{1}$, Enikő BITAY ${ }^{2}$ \\ ${ }^{1}$ Óbuda University, Bánki Donát Faculty of Mechanical and Safety Engineering, Institute of Materials \\ and Manufacturing Sciences, Department of Materials Technology Budapest, Hungary, \\ bagyinszki.gyula@bgk.uni-obuda.hu \\ ${ }^{2}$ Sapientia - Hungarian University of Transylvania, Faculty of Technical and Human Sciences, Targu Mures, \\ Romania,ebitay@ms.sapientia.ro
}

\begin{abstract}
The technological advantages of ultrasonic welding: (no requirement for filler metal; use of small electrical transient resistance contacts; ability to weld thin materials to thick materials) results in a helium-solid weld seam; the computer configuration of the welding parameters can easily be solved; clean and safe workflow (no sparks, flame or smoke); can be integrated into the production line. This article deals with some of the additional application features of this welding process.
\end{abstract}

Keywords: pressure welding, ultrasound, sonotrode, parameters, process variants.

\section{Physical basics and tools}

The microfriction (high frequency, micrometer amplitude vibration) energy -ultrasonic welding, utilizing the surface between the contact workpieces on the surface (,interface”) corresponding to the shape and size of the sonotrode (as a welding tool) - can also be considered as a special case of the friction welding achieved by vibration (not rotation) (Figure 1.).

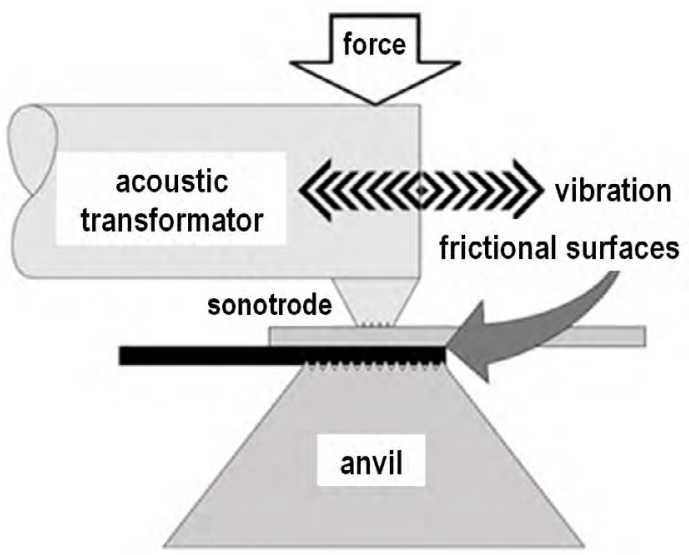

Figure 1. Ultrasonic welding, as high frequency, vibrating friction welding
The $50 \mathrm{~Hz}$ electromagnetic vibration (alternating voltage or current) is converted into mechanical vibration (ultrasound) or energy (20 to 40 $\mathrm{kHz}$ ). This energy transformation is performed by a resonator, which is

- a positive or negative longitudinal magnetostriction as a manifestation of the link between magnetization and mechanical tension of the ferromagnetic bodies, or

- electrostriction as a reciprocal piezoelectric effect based on this phenomenon.

When using magnetostriction, the alternating axial magnetic field generated by converting the low-frequency supply to the high frequency and the winding thereof is manifested as mechanical vibration (low amplitude longitudinal elastic deformation) in a magnetic field suitably located in a ferromagnetic material. The ferromagnetic (iron) core of the coil fed by the alternating current generates powerful longitudinal vibrations, i.e. emits ultrasonic waves if its own frequency is equal to the frequency of the alternating current $[1,2]$.

Electrostriction is the characteristic of the socalled active dielectrics; the elastic deformation due to the alternating electrical field (voltage), mechanical vibration, at a sufficiently high frequency (ultrasound). Due to the resonance ampli- 


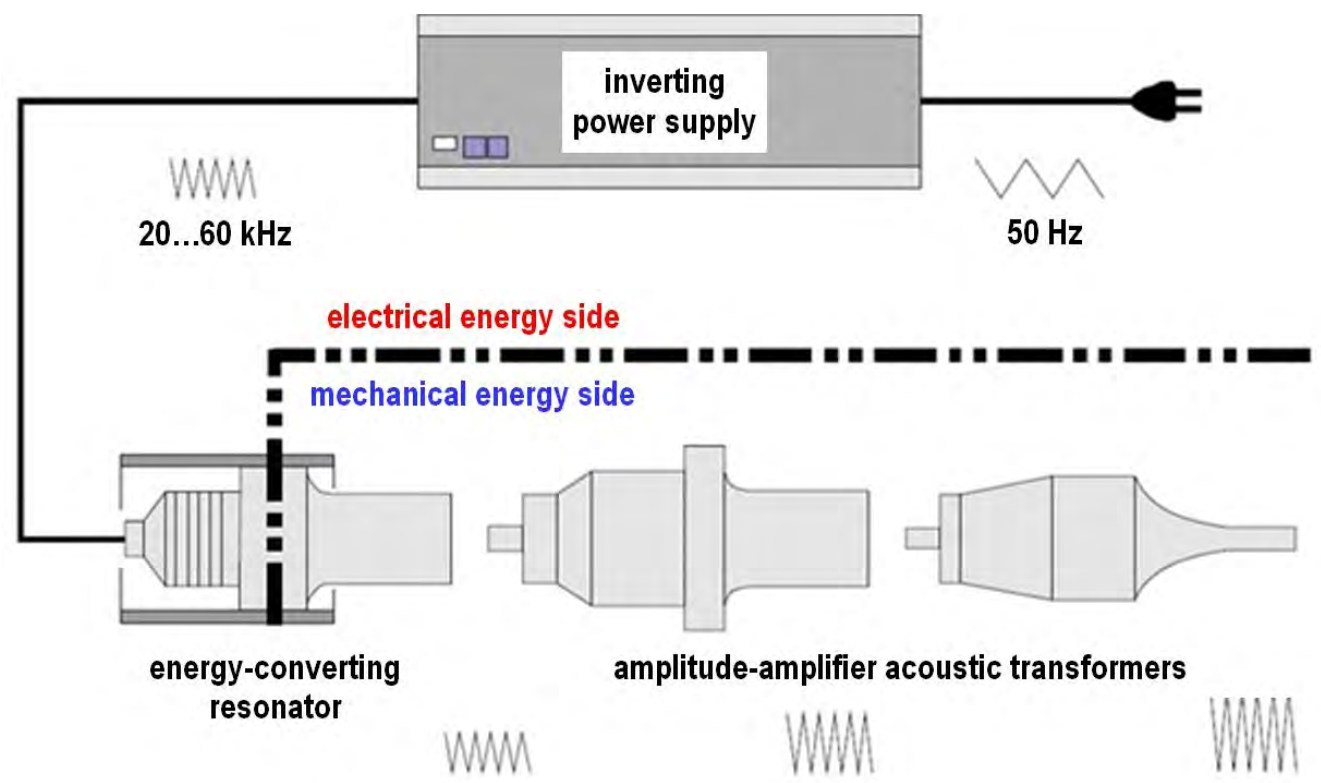

Figure 2. Ultrasonic welding equipment's main components

tude of this mechanical vibration, the frequency of vibrations of the electric field is the same as that of the dielectric body's own frequency [3, 4].

The mechanical vibration applied to the ultrasonic welding takes place on a sonotrode through a tuned acoustic transformer (s) (Figure 2.). The vibration transmitted to the components under compression forces the surface impurities and oxides to break off and create a pure, controlled diffusion seam. As the atoms are chemically linked between the welded portions, a real cohesion bond is created [5].

\section{Welding parameters}

The major technological parameters of ultrasonic welding are the vibration duration, the vibration amplitude and the (normal) force perpendicular to the vibration direction. Performance requirements for vibration generation and maintenance is given by:

$$
P=F \cdot A \cdot f=S_{m h} \cdot p_{\ell} \cdot \eta \cdot A \cdot f
$$

where $P$ is the performance [W], F is the force [N], A is the amplitude $[\mu \mathrm{m}], f$ is the frequency $[\mathrm{Hz}]$, $S_{m h}$ is the cross-sectional area of the pneumatic cylinder $\left[\mathrm{m}^{2}\right], p_{\ell}$ is the compressed air pressure [Pa], $\eta$ is the mechanical efficiency [-].

Then the energy demand for a welding cycle is:

$$
E=P \cdot \Delta t=F \cdot A \cdot f \cdot \Delta t=S_{m h} \cdot p_{\ell} \cdot \eta \cdot A \cdot f \cdot \Delta t
$$

where $E$ is the energy [J], $\Delta t$ the cycle time or weld time [s]. This time for most bindings is less than one second. If more energy is needed and all other technological parameters remain unchanged, the welding time should be increased.

It is necessary to create good quality welded joints so that the surfaces to be joined are clean. High-frequency friction (compression-free vibration) cleans the surfaces to be bonded at the beginning of the welding process. In the case of ultrasonic welding, differences in the surface state (inorganic non-metallic oxide layer, organic grease or oil contamination) can be compensated - by adjusting the time duration - by modifying energy value.

The resonator - acoustic transformer - sonotrode unit requires unimpeded minimum electrical power to initiate and maintain vibration motion. As the mechanical load increases, the power requirement required to maintain mechanical vibration increases. Friction due to pressure results in the welding by diffusion or local "stirring" of the base material.

By increasing the pressure - keeping the other parameters at a constant value - the mechanical load of the welding zone increases and the power, and power required to maintain the vibration also increases. By increasing the pressure - keeping the other parameters at a constant value - the mechanical load of the welding zone increases 
and the power and performance required to maintain the vibration also increases.

Ultrasonic equipment is a resonant acoustic device. Its amplitude is the difference in longitudinal extent and contraction $(5 . .35 \mu \mathrm{m})$ with which the tool actively vibrates. This amplitude corresponds to the friction distance of the welding surface. If the amplitude increases, the power required to maintain the increasing rate of vibration also increases. This will take less time to input the same energy.

Generally, the friction amplitude remains constant during a welding cycle. However, technical developments allow the amplitude of the sonotrode surface to be altered during the welding cycle. This amplitude profiling or stepping (Figure 3.) is mostly used for aluminium welding to increase bond strength and to prevent tool trapping.

When using ultrasonic devices, vibrations are transmitted through the acoustic device, resulting in harmonic resonance, consisting of nodes and "antinodes". This results in the resonant wave being transferred to the tool (Figure 4.).

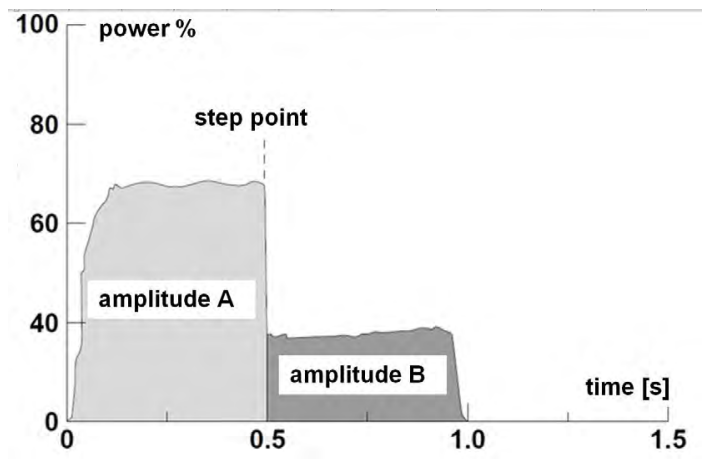

Figure 3. Amplitude profiling during ultrasonic welding [4]

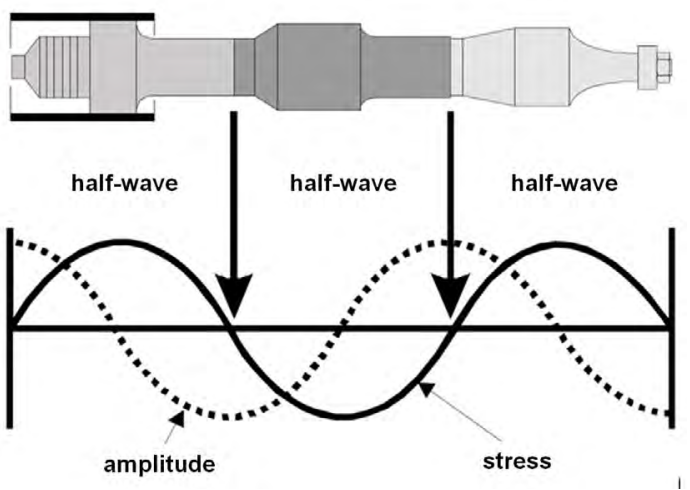

Figure 4. Harmonic resonance on ultrasonic device
The resonant wave transfer efficiency depends on the resonance frequency of the resonator-acoustic transformer-sonotrode unit and is determined by two main factors:

- the speed of sound (vibration) in the material, - the geometric shape of the acoustic unit.

It is possible to increase the amplitude and/or pressure to a point where the available power is no longer sufficient to generate or sustain vibration during the given mechanical load. At this point, the power supply stops, causing an overload condition. The electronic circuits of the system protect the power supply if such an overload condition occurs.

Ultrasonic welding results in a localized temperature increase due to the combined effects of flexible hysteresis, friction and plastic deformation. The welding surfaces reach roughly onethird of the melting temperature of the metals so that the physical properties of the welded materials practically do not change. As the ultrasonic welding process is an exothermic (heat-producing) reaction, the welding time increases the welding temperature.

\section{Process variants}

During ultrasonic spot welding, oscillating motion is transmitted from the overlapped inserts to the thinner $(0.005 \ldots 3 \mathrm{~mm})$. The sonotrode loaded with the force to compress the pieces creates a welded bond vibrating with this piece. It is important that there is a relative movement between the workpiece and not between the sonotrode and the upper workpiece. It is possible to connect sheets or wires of the same or different quality material.

Ultrasonic welding is a continuous spot welding in which the welded joint between the overlapping thin sheets evolve between the sonotrode and the anvil. During the welding of the ultrasonic circle (line), the alternating movement around the axis of the tubular sonotrode, is provided by three vibration units and thus, during sealing, a seam of approximately the same size and shape is formed with the tubular front surface of the sonotrode.

\section{Conclusions}

An ultrasonic welding process is defined by the quality of the material to be welded and its thickness. Based on the available equipment, the mechanical (and electric) performance, frequency, 
amplitude, compressive force and welding time should be determined based on the vibration damping ability of the material.

\section{Acknowledgement}

The authors wish to thank the EFOP-3.6.1-16-201600010 project - the Hungarian State and the European Union for their financial support.

\section{References}

[1] Ultrahangos hegesztés. In Hegesztés és rokon technológiák. Kézikönyv (ed. Szunyogh L. ) Gépipari Tudományos Egyesület, Budapest, 2007, 299-303.

[2] Bitay E., Bagyinszki Gy.: Robotok és a sajtoló hegesztések fejlesztései. In: A XXI. Fiatal müszakiak tudományos ülésszak előadásai. Proceedings of the $21^{\text {th }}$ international scientific conference of youngth engineers, Kolozsvár/Cluj, Kolozsvár, Románia, Műszaki Tudományos Közlemények 5. (2016) 101-104.

https://eda.eme.ro/handle/10598/29034

[3] Szilágyi M., Kovács T.: Ultrasonic welding application in case of aluminium sheet, Proceedings of 8th International Engineering Symposium at Bánki, Paper 55, 2016.

[4] Welder Touchscreen Controller - Instruction Manual - 2.5 Ultrasonic Theory, Branson Ultrasonic Corporation, Danbury, 2017

[5] Budó Á.: Kísérleti fizika I-III., Tankönyvkiadó, Budapest, 1985. 